\title{
Controle Social: práticas emancipatórias para garantia de direitos
}

\author{
Social Control: emancipatory practices \\ for the guarantee of rights
}

Anderson Carvalho Chaves*

\begin{abstract}
Resumo - O presente artigo aspira realizar uma discussão sobre o Controle Social democrático presente na Política Pública de Assistência Social, debate essencial no âmbito das Políticas Sociais no Brasil. Perpassamos, ainda, a importância do papel dos conselhos de Assistência Social e o processo de constituição da esfera pública, enfatizando as entidades de Assistência Social e destrinchando o conceito de sociedade civil nos marcos da democracia participativa para garantia de direitos. Utilizamos como metodologia uma revisão bibliográfica de análise teórica, com autores que estudam e debatem a referida temática, a partir das perspectivas teóricas marxista e gramsciana. Palavras-chave: controle social democrático; conselhos de assistência social; esfera pública; participação social.
\end{abstract}

\begin{abstract}
This article aspires to discuss the social democratic control present in the Public Policy for Social Assistance, an essential debate in Social Policies in Brazil. Furthermore, we approach the importance of highlighting the role of councils of Social Welfare and the process of constitution of the public sphere, emphasizing the role of social assistance entities and analyzing the concept of civil society within the framework of guaranteeing rights in a participatory democracy. We use as methodology a theoretical analysis literature review of authors who study and discuss such themes, from the theoretical Marxist and Gramscian perspectives.
\end{abstract}

Keywords: democratic social control; social assistance councils; public sphere; social participation.

\footnotetext{
*Assistente Social, Mestre em Serviço Social pela UERJ e Docente do Curso de Graduação da Universidade Candido Mendes. Correspondência: Rua Crispim, 85, Apt 101, Vila Emil, Mesquita, Rio de Janeiro. Brasil. CEP: 26551-301. Email: <andcarvalhochaves@hotmail.com>
} 


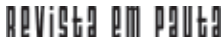

\} CONTROLE SOCIAL: PRÁTICAS EMANCIPATÓRIAS - CHAVES, A. C. \}

DOI: 10.12957/rep.2015.21073

\section{Introdução}

Neste artigo, iremos discutir a experiência dos Conselhos de Assistência Social na Política de Assistência Social brasileira, bem como o papel das entidades nos espaços de Controle Social democrático no Sistema Único de Assistência Social (Suas), ressaltando e enfatizando o controle democrático e a participação social. Pretendemos, também, aprofundar o debate teórico e conceitual sobre o Controle Social democrático, já que este pode ser considerado como um dos eixos norteadores da Política Nacional de Assistência Social de 2004, legislação que regula as bases de constituição do Suas.

Num primeiro momento, iremos relatar a experiência do Controle Social democrático no Suas e o papel das entidades da sociedade civil, destrinchando de maneira teórica, com alguns autores, o conceito de sociedade civil. Em seguida, aprofundaremos a temática do Controle Social democrático e a participação social no cenário contemporâneo.

\section{A experiência dos conselhos de assistência social no Suas e o papel das entidades nos espaços de Controle Social democrático}

A constituição dos espaços de democracia participativa possui seu marco legal inicial no art. 204 da Constituição de 1988, (BRASIL; 1988) que se refere à participação da população, por meio de organizações representativas, na formulação das políticas e no controle das ações em todos os níveis. Ainda na Carta Magna, no art. 194 do capítulo da Seguridade Social, ratifica-se o caráter democrático e descentralizado da gestão administrativa, com a participação da comunidade, em especial de trabalhadores, empresários e aposentados. Em suma, é na Constituição que se encontra prioritariamente a perspectiva de abertura legal de novos espaços de participação da sociedade civil no âmbito do Estado, tese que foi historicamente defendida nos trabalhos constituintes.

A regulamentação da Constituição Federal de 1988 promoveu o arcabouço jurídico institucional brasileiro dos conselhos de Assistência Social, respaldado na Lei Orgânica da Assistência Social (Loas), de 1993, acrescido da Lei 12.435/2011, que altera a Loas (Lei n 8.742/1993), dispondo sobre a organização da Assistência Social (BRASIL, 2010).

Segundo Behring e Boschetti (2006), exatamente para aperfeiçoar o processo democrático restrito à democracia representativa que foram criadas instâncias estratégicas como os conselhos, entendidas como arenas de discussão das demandas e interesses presentes em políticas setoriais específicas. Faz-se mister contextualizar a noção de esfera pública e de democracia no Brasil. Segundo Raichellis (2006, p. 80), a esfera pública pode ser entendida como: 


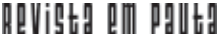

\} CONTROLE SOCIAL: PRÁTICAS EMANCIPATÓRIAS - CHAVES, A. C. \}

DOI: $10.12957 /$ rep.2015.21073

Um espaço essencialmente político, de aparecimento e visibilidade, aonde tudo que vem a público pode ser visto e ouvido por todos. Nesta esfera, os sujeitos sociais estabelecem uma interlocução pública, que não é apenas discursiva, mas implica na ação e na deliberação sobre questões que dizem respeito a um destino comum/coletivo.

Importante entendermos a noção de esfera pública como um espaço de ampliação da democratização da sociedade. Porém, este processo de participação social encontra ainda muitos entraves na real efetivação de sua constituição. Isto porque, no Brasil, convivemos por décadas com o modelo de autoridade centrado na figura do homem e do pai, vistos como grandes detentores e proprietários de terras, diretamente articulados com o poder político local. Fato que se torna incontestável no período que abrange a República Velha, no qual o estado de São Paulo configurava-se como detentor da produção cafeeira, e o de Minas Gerais como grande produtor de leite. Ou seja, a política coronelista propalada no meio rural expressa, de forma clara, a ausência de separação entre as esferas da vida pública e privada. Segundo a análise de Leal (apud REVISTA IDEIAS, 1999, p. 47), "o sistema coronelista representava a incursão do poder privado no poder público: não havia critérios transparentes, nos quais as ações públicas se fundamentassem".

Na verdade, os compromissos eram estabelecidos pelos princípios da palavra dada, referências da esfera do privado, do pessoal, favorecendo a implantação de uma "cultura da dádiva", dos favores políticos na barganha pela troca de votos dos coronéis (REVISTA IDEIAS, 1999). Desta forma, os direitos encontram-se totalmente mediados pelas relações de mando e de subserviência, transferidas da esfera do mundo privado para a esfera da vida civil, num conceito de cidadania restrita e consentida. Ressalta-se o histórico que permeia a própria concepção de Assistência Social no Brasil, que foi marcadamente influenciada pelas noções da esfera do mundo privado e da política dos coronéis.

Na década de 1930, no Brasil, a influência do populismo de Getúlio Vargas veio para intensificar este processo clientelista e paternalista da Política de Assistência Social que, neste período, era marcada pelo predomínio dos interesses privados em detrimento da noção de interesse público. Ou seja, a política era considerada um privilégio das elites dirigentes, consubstanciada pelas características de um Estado burguês, no qual a passividade e o distanciamento da população estavam atrelados a esta noção privatista e excludente. Percebe-se, neste período, um Estado altamente centralizador e controlador da sociedade civil, sendo a esfera pública sempre confundida com o espaço estatal.

No período do Governo Vargas, destacamos alguns marcos históricos importantes referentes à política de assistência social. Com o término da República Velha, a partir dos anos de 1930, a questão social se põe como alvo de intervenção estatal por meio das políticas sociais públicas. 
Ao mesmo tempo, o empresariado, imbuído de um novo espírito social, começa a criar mecanismos que visam à colaboração entre capital e trabalho, em substituição à mera repressão e assistência eventual e descontinuada.

A história da Política Pública de Assistência Social no Brasil nasce intrinsecamente atrelada ao Estado, num viés caritativo e de controle da sociedade, através do apassivamento das classes subalternas. Intensificouse, sobretudo, na ditadura do Estado Novo, no Governo Vargas, devido principalmente à preocupação do Estado com a disseminação das ideologias revolucionárias do fascismo na Europa.

Ao trabalhador pobre e sem carteira de trabalho assinada ou desempregado o que restava eram as obras sociais e filantrópicas, muitas das quais ligadas à ação social da Igreja Católica, que assistia aos mais pobres na sociedade. Assim foi criada a Legião Brasileira de Assistência Social (LBA) em outubro de 1942, por Darcy Vargas ${ }^{1}$, esposa de Getúlio Vargas. Nela, reuniam-se as senhoras da sociedade da época, sendo a primeira instituição assistencial de porte nacional para atender às famílias dos expedicionários brasileiros (Força Expedicionária Brasileira - FEB) chamados à Segunda Guerra Mundial, tornando-se uma sociedade civil de finalidades não econômicas. Para Sposati (2005, p. 20), "a assistência social como ação social é ato de vontade e não direito de cidadania".

Com o passar do tempo, a $\mathrm{LBA}^{2}$ começa a atender às famílias quando da ocorrência de calamidades, trazendo o vínculo emergencial à assistência social num viés tecnocrático, e não democrático. Terminada a guerra, a LBA se volta para a assistência à maternidade e à infância, iniciando a política de convênios com instituições sociais no âmbito filantrópico e do campo da benemerência, sendo caracterizada por ações assistencialistas e de prestação de auxílios emergenciais e paliativos à miséria. Neste contexto, cunha-se o chamado "primeiro-damismo", prática infelizmente persistente até os dias atuais nas gestões das Secretarias da Política de Assistência Social, embora seja, atualmente, mais presente nas gestões municipais.

Como foi dito, é no Governo Vargas que ressurge o primeiro-damismo, pautado no fato de a Assistência Social se associar à figura da primeira-dama. Começa, então, a se estabelecer, com a presidência da LBA na década de 1940, uma simbiose entre a iniciativa privada e a pública, conformando uma relação básica entre Estado e classes subalternas (SPOSATI apud TORRES, 2002).

Desta forma, a LBA integra o horizonte de uma política paternalista e clientelista na Assistência Social, cujo pressuposto é ser um "órgão" que

\footnotetext{
${ }^{1}$ Percebe-se que a prática do primeiro-damismo na área da Assistência Social é histórica no país, construída desde a gênese da política de Assistência Social.

2 No Governo Collor (1990-1992), a LBA sofreu uma série de escândalos com a então primeira-dama Rosane Collor, tais quais mau uso do dinheiro público, além de uma série de irregularidades. Isto aconteceu até sua completa extinção e, posteriormente, no Governo FHC, o que acarretou desrespeito e prejuízos diretos aos usuários de suas ações assistenciais.
} 


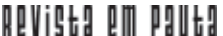

\} CONTROLE SOCIAL: PRÁTICAS EMANCIPATÓRIAS - CHAVES, A. C. \}

DOI: $10.12957 /$ rep.2015.21073

faz o bem e presta ajuda aos necessitados, estando ligado à primeira-dama do país e vinculado ao gabinete da Presidência da República. Desse modo, perdendo o status da tentativa de construir, na época, uma sólida política de Assistência Social em um ministério específico do governo. Neste caso, a Assistência Social passa a ser movida pela boa vontade dos governantes e pelas "mãos" generosas das primeiras-damas, fazendo com que as classes subalternas se conformem com a política instituída pelo governo. A ideologia dominante encontra terreno propício para a disseminação de suas ideias, costumes e valores condizentes com o posicionamento da burguesia.

Importante ressaltar que as classes subalternas possuem, no imaginário popular, a ideia de que as primeiras-damas da Assistência Social evocam papéis que envolvem generosidade e caridade humana, fazendo com que os usuários sejam levados a uma total passividade, conformidade e dependência das benesses institucionais do Estado. Ressalta-se, também, que o período ditatorial brasileiro (pós-1964) teve como propósito abafar e controlar as formas de organização dos trabalhadores pois, apesar da abertura ao capital industrial, vivia-se uma situação de arrocho salarial progressivo, em que a questão social assumia contornos assustadores no país, conforme nos aponta Torres (2002).

Além disso, neste período ditatorial no Brasil, as políticas sociais passam a ser utilizadas como estratégias do governo para arrefecer ou neutralizar os conflitos sociais. As iniciativas democráticas ameaçavam o governo ditatorial pela ação dos movimentos sociais, incentivados por grande parte da sociedade civil descontente e deteriorada no país. Nesta época, o Estado passa a assumir as rédeas da sociedade civil, criando um círculo de medo.

Somente após os anos 1970, a partir dos movimentos sociais contra o regime ditatorial, é que as organizações populares e sindicais começam a romper com os vínculos privados e clientelistas, com vistas ao estabelecimento de relações essencialmente públicas, não baseadas em favores pessoais, mas na conquista de direitos publicamente reconhecidos. Estes movimentos sociais podem se constituir como a gênese da noção de esfera pública no Brasil.

Desta forma, destaca-se o conceito de controle democrático, caracterizado, segundo a Revista Ideias (1999), como um processo de desprivatização do Estado, eliminando o acesso privilegiado dos interesses privados à agenda e às decisões do Estado e à construção da capacidade da sociedade civil de participar, de forma efetiva, na elaboração de uma agenda verdadeiramente pública. Tratando deste conceito, Pereira (2001) afirma que um Estado democrático se configura com a participação da sociedade nos fóruns de discussão sobre assuntos de interesse geral da coletividade, porém, sem abdicar de seu compromisso com o bem-estar dessa sociedade.

Dentro desta noção de esfera pública, Telles (1994) afirma que o espaço público emerge como uma possibilidade de instituir uma cultura de direitos. Assim, de substituir a questão do interesse privado como medida de todas as coisas, problema este cada vez mais reforçado pelos ditames do 


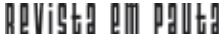

\} CONTROLE SOCIAL: PRÁTICAS EMANCIPATÓRIAS - CHAVES, A. C. \}

DOI: $10.12957 /$ rep.2015.21073

Estado neoliberal. A constituição da esfera pública investe de forma crucial contra uma das matrizes clássicas do ordenamento de nossa sociedade brasileira, que é o autoritarismo social.

Podemos citar, como experiências de constituição de uma esfera pública no Brasil, além dos espaços dos conselhos de política e de direitos, as conferências nos três entes federativos, bem como a criação e a implementação dos Fóruns de Políticas Públicas. Estes constituem um lugar importante na conquista dos direitos sociais a partir da Constituição de 1988. Destacam-se os Fóruns de Defesa dos Direitos da Criança e do Adolescente; o Fórum Nacional de Reforma Urbana; o movimento dos fóruns da Reforma Sanitária, que defendiam a proposta de gestão descentralizada e participativa da saúde, na constituição do Sistema UUnico de Saúde (SUS); e os Fóruns de Assistência Social que, no final da década de 1980 e no limiar da década de 1990, foram espaços importantes na formulação e promulgação da Lei Orgânica da Assistência Social (Loas), em 1993.

Apesar de toda a institucionalidade política e legal, a partir da Carta Cidadã de 1988 percebe-se, até os dias atuais, as dificuldades dos representantes da sociedade civil e dos movimentos sociais organizados brasileiros para se expressarem e reivindicarem os seus direitos e necessidades na esfera pública de negociação com o Estado.

Com base na concepção gramsciana de Estado ampliado, elencamos como mais uma experiência de constituição de esfera pública no Brasil o Orçamento Participativo. Este compreende a constituição de uma esfera pública não estatal, ou seja, não controlada pelo Estado. Tem um caráter indutivo, fiscalizador e controlador, cujas demandas são universais, e não de interesses privados, pois o que prevalece são os interesses majoritários da sociedade, reiterando a noção de uma democracia participativa.

Sendo assim, o conceito de esfera pública contrapõe-se aos interesses históricos dominantes que sempre tiveram acesso privilegiado ao Estado e à formação de ideologias burguesas no Brasil. Possibilitando, assim, a criação e a construção de espaços públicos coletivos, com a participação da sociedade civil organizada e, no caso da Política de Assistência Social, desde 2006, com a participação inclusive dos usuários dos serviços socioassistenciais do Suas. Incentiva-se, desse modo, um processo de radicalização democrática em busca de uma sociedade mais plural, participativa, equânime e politizada, ao menos no aspecto das normativas.

Desta forma, é inegável a importância da criação dos conselhos para a garantia de uma conquista histórica, somente possível pela luta incansável dos movimentos sociais progressistas, que abre espaços para a participação social e para o exercício da cidadania, conforma aponta Alves (2008). Importa, também, a questão da luta pela autonomia e pela garantia de infraestrutura necessária à operacionalização dos conselhos, pois, segundo aponta Stein (apud ALVES, 2008, p. 131): "O fator agravante é a estreita vinculação e dependência que os conselhos estabelecem com os órgãos gestores". 


\section{Revigta poll pallt}

\} CONTROLE SOCIAL: PRÁTICAS EMANCIPATÓRIAS - CHAVES, A. C. \}

DOI: $10.12957 /$ rep.2015.21073

Os conselhos de Assistência Social podem ser considerados como um dos condutos relevantes de participação da sociedade civil e de democratização da gestão governamental das políticas sociais. São um espaço privilegiado para o confronto e o debate dos interesses em disputa, além de espaço de consensos entre governo e sociedade civil.

Gramsci (1999) cria uma nova teoria do Estado, entendendo que ele não é mais o simples "comitê executivo da burguesia", embora permaneça um Estado de classes. O autor formula um conceito ampliado de Estado num contexto em que havia cada vez mais participação das massas na constituição da esfera política. Isto porque este Estado ampliado abarca a participação da sociedade civil e da sociedade política numa relação de disputa, na qual uma quer manter sua hegemonia ${ }^{3}$ sobre a outra.

Cabe ressaltar que a sociedade civil, para Gramsci (1999), referese aos partidos de massa, aos sindicatos e às diferentes associações, numa "crescente socialização da política", sendo denominadas pelo autor de "aparelhos privados de hegemonia". Pois elas devem ser entendidas como uma arena da luta de classes, ou seja, é neste espaço que as classes devem lutar para conquistar a hegemonia e tomar uma direção política, capacitando-a para a conquista e o exercício do governo. A sociedade política, para Gramsci (1999), significa a representação do Estado, manifestada através de ditadura, da coerção e da dominação. Tem como base material os "aparelhos coercitivos e repressivos" estatais, retratados por instituições jurídicas, penais, militares, policiais etc. Em suma, o Estado ampliado, para Gramsci (1999), é a junção entre a sociedade política, prevalecendo a ditadura e a coerção/ dominação, e a sociedade civil, na qual prevalece a hegemonia, o consenso e a direção.

Neste sentido, segundo Pedreira (2005), o Estado deve ser entendido como um espaço contraditório na luta de classes, já que absorve as demandas das classes subalternas, a fim de obter o consenso da sociedade. Para Gramsci (1999), o socialismo deve se implantar com base no consenso e não na simples coerção, pois o consenso, para o autor, baseia-se na hegemonia. Ou seja, na conquista da direção política e intelectual pelas classes subalternas, segundo Bravo (apud PEDREIRA, 2005, p. 32). Contudo, ressaltamos que a esfera dos conselhos deve ser entendida como referencial teórico gramsciano, como um espaço de disputa e de confronto entre o Estado e a sociedade civil.

$\mathrm{Na}$ análise dos conselhos de Assistência Social, a concepção de sociedade civil de Gramsci é importante, pois esta pode se constituir em um espaço onde as classes subalternas se articulem para a disputa do projeto hegemônico. Nesta perspectiva, segundo Pedreira (2005), o controle social é impulsionado pela relação contraditória presente na sociedade civil. Depen-

\footnotetext{
${ }^{3} \mathrm{Na}$ concepção gramsciana, a hegemonia é o poder de persuasão ou o predomínio do poder ideológico, e não apenas o poder coercitivo de uma classe sobre a outra.
} 


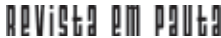

\} CONTROLE SOCIAL: PRÁTICAS EMANCIPATÓRIAS - CHAVES, A. C. \}

DOI: 10.12957/rep.2015.21073

dendo da correlação de forças, ora vai ao encontro dos preceitos da classe burguesa, na busca de consenso, muitas vezes representada pelo Estado, e ora vai ao encontro dos interesses das demandas das classes subalternas.

Importante destacar que, na ótica neoliberal, a sociedade civil não compõe o Estado, pois é vista, segundo Pedreira (2005, p. 33), como "o espaço do indivíduo que se torna necessário para impor limites aos interesses privados". Além disso, a sociedade civil, no neoliberalismo, é vista como homogênea, sem conflitos, reiterando a ideia de uma "passivização da sociedade civil".

Dito isto, para que os conselhos de Assistência Social possam de fato contribuir para um modelo de gestão participativa e democrática, é necessário que atualmente venhamos a observar alguns requisitos fundamentais, segundo a análise de Campos (2006), como por exemplo: a importância de que os conselhos de Assistência Social tenham uma sólida representatividade sociopolítica, que garanta a paridade entre governo e sociedade civil, ou seja, uma representatividade de movimentos combativos; a necessidade precípua de o conselho ser mobilizado e mobilizador, possuindo um planejamento de ações de suas atividades e reuniões; a necessidade ímpar de dispor de infraestrutura (recursos materiais, humanos e financeiros) condizente para o seu pleno exercício; a necessidade de se ter acesso regular às informações (transparência) acerca de recursos, metas, valores de investimento nos projetos e programas sociais na rede de proteção social básica e especial; valores dos pisos básicos fixo, de transição e variável, de acordo com o exposto na NOB/Suas 2012; redes de serviços locais e a importância de se observar o funcionamento do Fundo Municipal de Assistência Social. Em suma, estas são questões que devem ser tratadas nas reuniões dos conselhos locais, incentivando a transparência pública e a possibilidade de se ter uma política de capacitação regular, tanto para os conseIheiros do governo quanto para os da sociedade civil, incluindo as entidades prestadoras dos serviços, entidades de defesa de usuários e de representantes de trabalhadores.

Contudo, observa-se que os conselhos de políticas públicas, e em especial os conselhos de Assistência Social, possuem uma "polaridade de posicionamentos contrastantes", pois são vistos como instrumentos de democratização das relações de poder na gestão das políticas públicas, sendo encarados como uma arena de conflitos em disputa. Ou, por outro lado, são vistos como uma forma de colaboração e cooptação da sociedade civil por parte do Estado, espaços minados/cooptados, onde as diferenças desaparecem, prevalecendo uma hegemonia conservadora.

Neste último aspecto, é relevante a concepção teórica de Junger Habermas, que entende a sociedade civil como homogênea, já que esta não apresenta antagonismos e conflitos, ou seja, é de natureza consensual. Para Habermas (2003) há uma valorização da sociedade civil desmembrada do Estado e do mercado, e esta concepção tem contribuído para a noção 


\section{Revigta poll paltg}

\} CONTROLE SOCIAL: PRÁTICAS EMANCIPATÓRIAS - CHAVES, A. C. \}

DOI: 10.12957/rep.2015.21073

de sociedade civil enquanto provedora de bens e serviços, conhecida como "terceiro setor" e "organizações não governamentais". Na análise habermasiana, o Controle Social é entendido como controle da sociedade civil, sendo esta considerada homogênea, sem conflitos de classe e portadora de interesses universais, sobre o Estado, que é neutro e está acima das classes sociais, segundo Correia (apud PEDREIRA, 2005, p. 35).

Para Bravo (apud PEDREIRA, 2005) existem três concepções teóricas de conselhos de políticas públicas: espaços em disputa (concepção gramsciana); espaços de consensos (sob a ótica de Habermas) e, ainda, espaços de cooptação da sociedade civil por parte do poder público (sob a ótica do pensamento de Althusser). Segundo análise de Mészáros (apud SILVA, 2005), refletindo sobre o poder de controle do capital, que por si só é destrutivo e incontrolável, parte-se da premissa de que os conselhos podem se constituir como uma das formas de controle do Estado, sob a ótica do capital, mas também do trabalho. Porém, do lado dos trabalhadores, de acordo com Abreu (apud SILVA, 2005, p. 158), "Os conselhos podem se constituir como espaços de expressão política da classe trabalhadora, na luta pela garantia de meios à própria reprodução material e subjetiva".

\section{A constituição da esfera pública no Brasil}

A consolidação da democracia no Brasil passa por uma insistente vontade política para a construção de uma esfera pública que seja nacional, soberana, consistente e visível. Raichellis (apud BEHRING; BOSCHETTI, 2006) aponta alguns componentes essenciais para a construção de uma esfera pública democrática, a saber: visibilidade, controle social, representação de interesses coletivos, democratização e cultura pública. Sendo assim, Raichellis (1998), afirma que:

A esfera pública é o lócus da Publicização ${ }^{4}$, que se funda numa visão ampliada da democracia, tanto do Estado quanto da sociedade civil e na implementação de novos mecanismos e formas de atuação, dentro e fora do Estado, que dinamizem a participação social para que ela seja cada vez mais representativa da sociedade.

A grande questão a se ressaltar neste debate é levar adiante a concepção de Controle Social como espaço de disputa e de embate político, imprimindo aos conselhos e conferências o espírito democrático de construção da esfera pública e de aprofundamento da democracia. É muito complexo mobilizar a sociedade civil a fim de que venha a participar das

\footnotetext{
${ }_{4}^{4}$ Publicização, neste contexto, deve ser entendida no sentido de tornar público, ou melhor, de tornar os recursos públicos de mais transparentes, na construção de uma esfera pública como espaço de explicitação de interesses em conflito e de confronto de projetos sociais.
} 


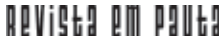

\} CONTROLE SOCIAL: PRÁTICAS EMANCIPATÓRIAS - CHAVES, A. C.

DOI: $10.12957 /$ rep.2015.21073

instâncias de Controle Social, das audiências públicas, por exemplo, a começar pelo municipal, devido ao fato de enfrentarmos obstáculos econômicos, políticos e culturais seculares no nosso contexto social. Ressaltase, por exemplo, a dificuldade de mobilização e de conscientização do papel do Controle Social por parte da sociedade civil na esfera local. Há um desgaste e uma fragmentação das entidades da sociedade civil, desde fins da década de 1990, que foram intensificados com o poderio do Estado neoliberal e a precarização dos vínculos da parceria público-privado, principalmente na política de Assistência Social.

Behring e Boschetti (2006) questionam se o espaço dos conselhos está sendo verdadeiramente o locus de uma nova articulação entre Estado, sociedade civil e afirmação de direitos. Há, efetivamente, o Controle Social da sociedade civil sobre o governo, a ponto de os conselhos serem um espaço de reivindicação e de transparência nas prestações de contas da Política de Assistência Social, principalmente locais? De acordo com as autoras, há conselhos que não deliberam e há até mesmo aqueles em que os conseIheiros da sociedade civil são indicados pelo próprio poder governamental, a partir de critérios discutíveis e particularistas, num controle extremamente autoritário e inadmissível sobre a sociedade civil, que deve ser autônoma para escolher seus representantes. Na verdade, os governos desejam ter uma sociedade civil bem comportada, cordata, "amiga do governo", para que facilite e contribua para a governabilidade dos gestores, reproduzindo a arraigada cultura política brasileira clientelista.

Na Política de Assistência Social, a concepção dos conselhos pode envolver a cooptação de diversas entidades por métodos clientelistas, com maior ou menor sutileza, até regulamentações que não respeitam a legislação da área. Esta centralização e contextualização do poder nas mãos do governo acabam por descaracterizar o verdadeiro sentido das instâncias de Controle Social (BEHRING; BOSCHETTI, 2006).

Ora, a sociedade civil não é homogênea, sendo atravessada por interesses e tensões que fazem parte de um ambiente cindido, fragmentado e de classes, além de outras contradições. Assim, se antes organizada, a sociedade civil fica literalmente "nas mãos do governo", pois nem todos os representantes destas entidades defendem os interesses da coletividade; muitos estão buscando interesses próprios, na tentativa de conseguir algum benefício para as instituições que representam, inclusive do ponto de vista financeiro.

Segundo a análise de Correia (apud SOUZA, 2010, p. 71), o Controle Social deve ser entendido como "o controle da sociedade sobre o destino das políticas sociais para que atendam aos reais interesses da maioria da população". Esta autora enfatiza e reconhece os limites e contradições que possui o Controle Social, pois, à medida que pode aglutinar frações da classe trabalhadora na fiscalização das ações do Estado e no nosso caso, na Política de Assistência Social, também pode fortalecer o poder institucional 


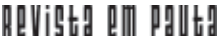

\} CONTROLE SOCIAL: PRÁTICAS EMANCIPATÓRIAS - CHAVES, A. C. \}

DOI: 10.12957/rep.2015.21073

e facilitar a criação de mecanismos de manipulação e de cooptação de lideranças dos movimentos sociais. Percebe-se isto nos conselhos municipais e nas instâncias locais, por exemplo.

Outro limite importante que a autora aponta é de que os objetivos do Controle Social estão cada vez mais na contramão dos interesses públicos da coletividade, principalmente com o refluxo dos movimentos sociais na era do neoliberalismo, com mais ênfase a partir da década de 1990. Atrelado a isto, muitos conselhos têm servido apenas como um espaço para garantir o repasse de recursos financeiros e subsídios para a rede privada, em detrimento da ampliação da rede pública. Cabe salientar que a experiência dos conselhos, no Brasil, não pode ser considerada como único conduto da participação política e nem como exemplo modelar de uma sociedade civil organizada. Os conselhos representam apenas uma das formas de participação, que necessita de acompanhamento e avaliação, de maneira atenta, com outras modalidades de organização e mediação políticas.

Para Raichellis (2006), a interferência governamental vai desde a sonegação de informações, principalmente relativas ao orçamento e decisões governamentais, até a nomeação dos representantes da sociedade civil sem a mediação de processo eleitoral democrático. Isto resulta na manipulação do governo nas regras de eleição, cooptação de conselheiros e presidência etc.

Podemos elencar, na NOB/Suas (Resolução CNAS 33/2012), em seu art. no 115, algumas estratégias importantes para o fortalecimento dos conselhos e das conferências de Assistência Social e promoção da participação dos usuários:

Planejamento das ações do conselho de assistência social; ampliação da participação popular; valorização da participação dos trabalhadores do SUÁS; participação dos conselhos e dos usuários no planejamento local, municipal, estadual, distrital, regional e nacional; convocação periódica das conferências de assistência social e valorização da participação das entidades e organizações de assistência social. (BRASIL, 2013 p. 33).

Mota (2010) ressalta que, dos anos 1980 para a década de 1990, o conceito de sociedade civil estava atrelado à ampliação da democracia e da cidadania. Além disso, na década de 1990 e nos idos dos anos 2000 há um apelo recorrente para que a sociedade civil colabore com o Estado na execução das políticas sociais, através dos "chamados convênios com as entidades assistenciais". Este apelo é uma das principais estratégias que se constroem para neutralizar os conflitos e apagar as diferenças de projetos societários. Baseado no pensamento político de Gramsci, as iniciativas de envolver a sociedade civil nas ações estatais são constituidoras da hegemonia dominante, ressaltando as ideias de passivização e de transformismo, implicando, assim, na absorção da tendência antagonista, na neutralização das lutas sociais e na destituição do caráter de classe das práticas sociais das entidades. 


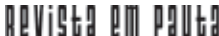

\} CONTROLE SOCIAL: PRÁTICAS EMANCIPATÓRIAS - CHAVES, A. C. \} DOI: $10.12957 /$ rep.2015.21073

A sociedade civil é pensada no campo da tradição marxista como um lugar de movimento e de contradições, bem como campo de construção de hegemonia das classes subalternas e elevação intelectual, moral e política dos dominados. No atual momento de reestruturação do capital e reforma do Estado, no entanto, a sociedade civil, impulsionada pelo neoliberalismo, postula uma autonomia em relação ao Estado, com vistas à "desideologizar" as práticas classistas e de ocultar as diferenças sociais em prol da legitimação das forças dominantes estatais. Silva (2005), nesse contexto, destaca a criação de mecanismos de subordinação, que retiram o caráter contraditório da sociedade civil, resgatando elementos de colaboração e consenso determinantes da natureza e do conteúdo de sua intervenção na sociedade.

$\mathrm{Na}$ verdade, neste contexto, prevalece a ótica do interesse privado, em detrimento do interesse da coletividade; ou seja, a sociedade capitalista desigual tende a perpetuar relações sociais que buscam benefícios para si próprios, e não como espaço de interlocução política visando ao interesse coletivo, mas buscando beneficiar a classe burguesa. Contrapondo esta questão à concepção clássica de Rousseau (século XVIII), a sociedade civil organizada tem entre seus propósitos "propiciar aos cidadãos maior integração sociopolítica, desenvolvendo em cada um a sensação de pertencimento a sua comunidade, tornando as decisões coletivas mais aceitas pelo conjunto dos indivíduos" (ROUSSEAU apud CAMPOS, 2006, 45).

Segundo análise de Montaño (2010), o conceito de terceiro setor pode ser designado como as ações das organizações e/ou atividades da sociedade civil de caráter não estatal e não mercantil. Devemos entender este conceito numa perspectiva crítica e de totalidade, pois se refere a um fenômeno real que ao mesmo tempo está inserido e é produto da reestruturação do capital, pautado nos princípios neoliberais. Tem instaurado uma nova modalidade e um novo padrão de resposta à questão social, seguindo os valores da solidariedade local, da autoajuda e da ajuda com base em práticas de incentivo ao voluntariado. Como exemplo, temos as Organizações Não Governamentais (ONGs), Organizações de Sociedade Civil de Interesse Público (Oscip), as fundações empresariais filantrópicas etc.

Analisando de forma crítica e contundente o projeto neoliberal que elabora esta nova modalidade de resposta à questão social, tem como propósito acabar com a condição de direito posto nas políticas sociais e assistenciais de caráter universalista, com a igualdade de acesso em troca das solidariedades sociais e empresariais, segundo Montaño (2010). A partir da concepção das Políticas Sociais neoliberais, de acordo com Soares (apud MONTANO, 2010, p. 194), "estas limitações no novo padrão neoliberal de política social estatal são caracterizadas pela primazia de programas assistenciais de caráter apenas suplementar e emergencial, dirigidos apenas para os pobres".

Todo este processo histórico de articulação entre Estado e sociedade civil tem influído de forma decisiva no papel das entidades da 
sociedade civil organizada, nas instâncias de Controle Social, como o espaço dos conselhos, por exemplo. Isto porque, na Política de Assistência Social, este fato é bastante real, uma vez que estas entidades não estão preocupadas com o espaço das lutas coletivas, mas com os interesses voltados para o benefício das suas instituições.

O estabelecimento destas parcerias acaba por fazer com que o Estado deixe de executar aquilo que é de sua responsabilidade, descentralizando, repassando recursos via parceria ao setor privado e facilitando legalmente as atividades das ONGs, Oscips etc., dando respostas às necessidades sociais pontuais e localizadas, de acordo com as necessidades dos entes públicos federativos. Estas funções de parceria entre o Estado e as ONGs acabam por gerar a aceitação da população, num processo estritamente ideológico e funcional à reestruturação do capital.

Diante do quadro anteriormente exposto referente à política de Assistência Social, pode-se afirmar que a experiência da participação popular torna-se cada vez mais difícil no contexto político do país, pois mesmo estando regulamentada pela Constituição e pela Loas, mais especificamente nas diretrizes da Assistência Social - art. 5º, inciso II -, esta experiência transforma-se em um verdadeiro desafio nas instâncias de Controle Social das três esferas de governo. Isto ocorre devido ao fato de o poder econômico caminhar paralelamente ao poder político, estabelecendo relações clientelistas e privatistas, beneficiando alguns em detrimento de todos.

De acordo com Behring e Boschetti (2006), se a experiência dos conselhos se espalhou territorialmente em quase todos os municípios brasileiros, não significa que houve uma redemocratização efetiva do Estado. Por outro lado, tem-se analisada e reconhecida a importância de outros mecanismos de Controle Social, como o Ministério Público, a imprensa, os conselhos de fiscalização das profissões, tais quais o conjunto CFESS-Cress. A tentativa é priorizar o fortalecimento dos movimentos sociais num período marcado pela ofensiva neoliberal conservadora, que destitui a esfera do coletivo em detrimento do primado do indivíduo.

Recentemente, em meados de 2013, vimos a mobilização de diversos setores da sociedade civil contra as posturas políticas do governo brasileiro, gerando e fomentando manifestações coletivas. Estas, portanto, vão de encontro ao espírito da democracia participativa e à noção de Controle Social que temos adotado neste texto.

\section{Controle Social democrático e participação social no cenário contemporâneo}

Face ao exposto, salientamos que enormes são os desafios postos para efetivação da participação e Controle Social democrático na atual conjuntura. Podemos afirmar, com base no trabalho de Chaves (2013), 


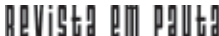

\} CONTROLE SOCIAL: PRÁTICAS EMANCIPATÓRIAS - CHAVES, A. C. \}

DOI: 10.12957/rep.2015.21073

que a participação da sociedade civil organizada está cada vez mais escassa e difícil, principalmente na esfera dos conselhos de Políticas Públicas, em especial nos conselhos de Assistência Social. Este fato tem ocorrido principalmente pelo próprio processo de fragmentação e esgarçamento dos influxos neoliberais, que vem atingindo de forma fulcral o limiar da sociedade neste início do século XXI.

Vale ressaltar o histórico da política de Assistência Social no contexto brasileiro, assegurada como política pública, que integra a Seguridade Social pós-Constituição Federal de 1988. Ainda, que luta para romper com seu histórico tradicional, já que fora configurada durante um longo período como filantropia, caridade e benemerência, além de ser utilizada como uma prática clientelista e paternalista no curso da história deste país.

Yazbek (2009) apresenta a categoria "subalterna" para nomear as classes em que se inserem os usuários das políticas sociais. A subalternidade diz respeito à ausência de poder de mando, de poder de decisão; faz parte do mundo dos dominados e dos submetidos à exclusão social, econômica e política, sendo introjetada ao longo da história brasileira. A autora afirma que este padrão arcaico de relações fragmenta e desorganiza os subalternos ao apresentar como favor ou como "vagabundagem" aquilo que é direito. Sendo assim, neste contexto, fomentar a participação dos usuários para exercer o Controle Social é um desafio a ser enfrentado continuadamente, uma vez que o público da Assistência Social historicamente se coloca como não direito.

Outra questão a ser destacada, conforme o trabalho de Chaves (2013), é o modo com que as entidades da sociedade civil organizada têm se desmobilizado e perdido a sua força política perante os governos municipais, no que tange a conseguir estratégias de participação, de embate e de propostas participativas referentes à política de Assistência Social. No entanto, há algum avanço dos movimentos sociais de participação dos usuários da Assistência Social, nos moldes da Resolução CNAS 24/2006, que coloca os usuários como sujeitos ativos do processo de participação social. Ainda assim, na esfera dos conselhos e das conferências de Assistência Social, e mais particularmente no Conselho de Assistência Social de Mesquita (CHAVES, 2013), tem sido percebida uma falta de interesse e entendimento dos aspectos técnicos do que vem a ser a Política de Assistência Social na atualidade, com seus marcos legais reguladores. Nota-se, neste aspecto, que há uma ausência de capacitação e de mobilização da sociedade civil organizada e dos usuários dos serviços socioassistenciais da política. Falta, também, entender, desmistificar e lutar por melhorias desta política no território, na conquista e na efetivação dos direitos sociais garantidos na Lei Orgânica da Assistência Social.

Desta forma, como estratégia, podemos elencar quatro aspectos importantes dentro desta temática. O primeiro aspecto já foi aqui ressaltado: consiste no enorme desafio de fomentar a participação dos usuários da 


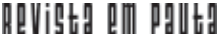

\} CONTROLE SOCIAL: PRÁTICAS EMANCIPATÓRIAS - CHAVES, A. C. \}

DOI: $10.12957 /$ rep.2015.21073

Assistência Social, de modo a se compreenderem como sujeitos de direitos sociais. No segundo aspecto, vemos a necessidade de investimento em uma capacitação política e ética, e não apenas técnica, para os conselheiros, visando à sua conscientização na garantia dos direitos sociais. O terceiro aspecto é que esta capacitação deveria ser fornecida prioritariamente pela universidade, e não por profissionais do próprio poder executivo, facilmente cooptados pelo governo, principalmente aqueles não concursados, ou seja, que possuem cargo de nomeação ou são regidos por contratos instáveis de trabalho. O quarto aspecto é a realização e planejamento dos Fóruns da Assistência Social pela Sociedade Civil para estimular a participação e o engajamento das entidades, dos trabalhadores do Suas e dos usuários dos Serviços Sociais, com vistas ao fortalecimento destes segmentos da sociedade civil.

Destacamos neste trabalho, por fim, a importância do papel do Controle Social na construção e na democratização da política de Assistência Social municipal. Desse modo, buscou-se reforçar o protagonismo dos usuários e o envolvimento do assistente social como profissional que pode estimular um trabalho de base, de democratização com os usuários dos equipamentos públicos da Assistência Social e das entidades privadas, na lógica de reforçar a institucionalização do Suas. Este reforço passa pela esfera do Conselho Municipal de Assistência Social, com todos os seus meandros e complexidades que ora tratamos aqui.

Em suma, estas são as principais estratégias que servirão como defesa para o aprofundamento do Projeto Ético-Político Profissional do Serviço Social, sendo de fundamental importância o engajamento dos assistentes sociais, com vistas a contribuir com a conscientização política dos conselheiros, em especial os da sociedade civil.

\section{Considerações finais}

Salientamos, neste artigo, a construção do Controle Social democrático na sociedade brasileira, presente na política pública de Assistência Social. Perpassamos, assim, a necessidade de ressaltar o papel dos conselhos de Assistência Social, bem como o processo de constituição da esfera pública no Brasil e a participação da sociedade civil.

Sublinhamos a importância de pensar o Controle Social numa perspectiva marxista, como o embate realizado entre a classe burguesa, representada pelo Estado detentor dos meios de produção e de reprodução social, e a classe trabalhadora, que são os usuários desta política de Assistência Social. Estes são ainda subalternizados historicamente na garantia de seus direitos sociais, principalmente na esfera do poder executivo. Devido a esta subalternidade histórica, muito bem relatada por Yazbek (2009), há um desafio enorme no que tange ao estímulo à participação e ao Controle Social dos usuários nesta política pública. 


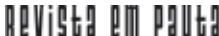

\} CONTROLE SOCIAL: PRÁTICAS EMANCIPATÓRIAS - CHAVES, A. C.

DOI: 10.12957/rep.2015.21073

Vale destacar, também, que os equipamentos públicos da Assistência Social nos territórios devem ser espaços de fiscalização e monitoramento por parte das instâncias de Controle Social, principalmente dos conselhos de Assistência Social e, quiçá, do Ministério Público. A presença destes nas áreas citadas faz com que a perspectiva dos conselhos seja um locus importante para a efetivação e concretude da intersetorialidade no patamar da Política Pública de Assistência Social no Brasil. Desse modo, garantindo sempre o viés da democracia participativa, ou seja, com ampla participação da sociedade civil e fortalecimento da esfera pública no país.

Evidenciamos a importância de criar, na Política de Assistência Social, espaços alternativos para o desenvolvimento do Controle Social, como a criação de Fóruns de Assistência Social regionais, estaduais e nacionais, além de comitês, plenárias e audiências públicas envolvendo a sociedade civil organizada, o poder executivo e os usuários dos serviços socioassistenciais, principalmente da esfera municipal.

Pontuamos, ainda, o desafio de constituir verdadeiros sujeitos sociais ativos nestes espaços de participação e Controle Social. Em época de Conferência de Assistência Social, há um engajamento de segmentos da sociedade civil; porém, em outros momentos, esta participação fica esvaziada, não havendo um trabalho de continuidade deste processo democrático. Isto tem facilitado a ineficiência e a falta de resolutividade do poder público nas ações e serviços prestados aos equipamentos da Assistência Social, como os CRAS, Creas, entidades de acolhimento institucional etc. Percebemos e enfatizamos, neste trabalho, a fragilidade do nível de organização dos cidadãos e dos movimentos sociais, dado os influxos neoliberais na conjuntura brasileira.

Observamos que a experiência dos conselhos se espalhou territorialmente, o que não significa que houve uma real redemocratização do Estado brasileiro. Conforme Behring e Boschetti (2006), ressalta-se a importância de outros mecanismos de Controle Social, como o Ministério Público, a imprensa, os conselhos de fiscalização das profissões, dos quais destaca-se o conjunto CFESS-Cress, na tentativa de priorizar o fortalecimento dos movimentos sociais, num período marcado pela ofensiva neoliberal conservadora. Esta destitui a esfera do coletivo, em detrimento do primado do indivíduo.

Face ao exposto, acreditamos que há a necessidade de fortalecimento das instâncias de Controle Social democrático, mesmo em meio à avalanche neoliberal de retrocesso dos direitos sociais públicos, deixando de priorizar a esfera privada individual, em detrimento da esfera pública, coletiva. Desse modo, haverá uma real efetivação e garantia de direitos sociais da população usuária e demandatária dos serviços sociossistenciais da política pública de Assistência Social no Brasil, em tempos de ajuste estrutural. 


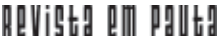

\} CONTROLE SOCIAL: PRÁTICAS EMANCIPATÓRIAS - CHAVES, A. C. \}

DOI: 10.12957/rep.2015.21073

\section{Referências}

ALVES, A. A. F. Assistência social - história, análise crítica e avaliação. Curitiba: Juruá. 2008.

BEHRING, E. R.; BOSCHETTI, I. Política social: fundamentos e história. São Paulo: Cortez Editora. 2006.

BRASIL. Constituição da República Federativa do Brasil. 1 o edição. 1988. BRASIL. Ministério do Desenvolvimento Social e Combate à Fome (MDS). Lei n. 8742, de 07 de dezembro de 1993. Lei Orgânica da Assistência Social Anotada. Brasília: Secretaria Nacional de Assistência Social (SNAS). 2010.

Resolução CNAS 33, de 12 de dezembro de 2012. Aprova a Norma Operacional Básica do Sistema Único de Assistência Social (NOB/Suas). Brasília: Diário Oficial da União. 3 jan. 2013.

CAMPOS, E. B. Assistência social: do descontrole ao controle social. Revista Serviço Social e Sociedade, São Paulo: Ed. Cortez, n. 88. 2006.

CHAVES, A. C. O Controle social na construção e democratização da política de Assistência Social: o papel dos conselhos e a realidade de um município da Baixada Fluminense. Dissertação (Mestrado) - UERJ. 2013.

GRAMSCI, A. Cadernos do cárcere. Introdução ao estudo da filosofia. A filosofia de Benedetto Croce. Rio de Janeiro: Civilização Brasileira. 1999. HABERMAS, Junger. Teoria Crítica de Habermas. Disponível em: http:/ www.geocities.com/Eureka/2330/hab3.htm. Acesso em 22 de mai. de 2013. MONTAÑO, C. Terceiro setor e questão social: crítica ao padrão emergente de intervenção social. São Paulo: Cortez Editora. 2010.

MOTA, A. E. (org.). O mito da assistência social: ensaios sobre Estado, política e sociedade. São Paulo: 4ํe edição. Cortez Editora. 2010.

PEDREIRA, R. S. Saúde e controle social: uma análise comparativa entre os assistentes sociais e demais profissionais de saúde - Hospitais Universitários (RJ). Trabalho de Conclusão de Curso (Graduação em Serviço Social) Universidade do Estado do Rio de Janeiro (UERJ), Rio de janeiro. 2005.

PEREIRA; Potyara Amazoneida Pereira. "Estado, regulação social e controle democrático". In: BRAVO, M. I. S.; PEREIRA, P. A. P. (org.). Política social e democracia. Rio de Janeiro: Uerj. 2001.

RAICHELLIS, R. Esfera pública e conselhos de assistência social: caminhos da construção democrática. São Paulo: Cortez. 1998.

. Democratizar a gestão das políticas sociais - um desafio a ser enfrentado pela sociedade civil. In: MOTA et al. (org.). Serviço social e saúde: formação e trabalho profissional. São Paulo: Cortez Editora. 2006. 


\section{Revigta all palth}

\{ CONTROLE SOCIAL: PRÁTICAS EMANCIPATÓRIAS - CHAVES, A. C.\}

DOI: $10.12957 /$ rep.2015.21073

REVISTA IDEIAS. Esfera pública e democracia no Brasil. Campinas. 1999. SILVA, J. A. F. Sociedade civil e conselhos de assistência social: contradição entre o adensamento e o esvaziamento da participação. Dissertação (Mestrado do Programa de Pós-Graduação em Serviço Social) - Universidade do Estado do Rio de Janeiro, Rio de Janeiro. 2005.

SOUZA, R. M. de. Controle social e reprodução capitalista: polêmicas e estratégias contemporâneas. Revista Temporalis, Brasília (DF), ano 10, n. 20, jul./dez. 2010.

SPOSATI, A. A menina Loas: um processo de construção da assistência social. São Paulo: Cortez. 2005.

TELLES, V. da S. A sociedade civil e a construção de um espaço público. In: DAGNINO, E. (org.). Os anos 90: política e sociedade no Brasil. São Paulo: Brasiliense. 1994.

TORRES, I. C. As primeiras-damas e a assistência social: relações de gênero e poder. São Paulo: Cortez. 2002.

YAZBEK, M. C. Classes subalternas e assistência social. São Paulo: Ed. Cortez. 2009.

Recebido em 06 de janeiro de 2015.

Aprovado para publicação em 11 de março de 2015.

DOI: 10.12957/rep.2015.21073

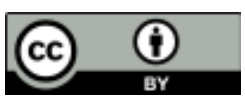

A Revista Em Pauta: Teoria Social e Realidade Contemporânea está licenciada com uma Licença Creative Commons Atribuição 4.0 Internacional. 